\title{
Los derechos fundamentales de la Constitución Política de 1991 como resultado de un proceso constituyente deliberativo ${ }^{* * * * * * * * * *}$
}

\section{The Bill of Rights of the Constitution of 1991 as result of a constitutional deliberative process}

\section{RESUMEN}

El proceso de construcción de la Constitución Política de 1991 fue una respuesta a complejos fenómenos sociales como el narcotráfico, la persecución política de la izquierda nacional y el uso excesivo del "Estado de sitio". Esto condujo a que distintos movimientos sociales vieran en la estructuración de un nuevo acuerdo político una forma legítima de establecer un paradigma democrático que garantizara el respeto de los derechos fundamentales y la

Magíster en Derecho de la Universidad de los Andes. Abogado y magíster en Derecho Administrativo de la Universidad Libre de Colombia. Docente investigador de la Universidad Libre. Bogotá, Colombia. Contacto: ea.leiva60@uniandes.edu.co y ericleiva3@gmail.com

** Doctor en Ciencia Política de la Universidad de Santiago de Compostela (España). Abogado de la Universidad Católica de Colombia y profesional en Ciencias Políticas y Administrativas de la Escuela Superior de Administración Pública (ESAP). Profesor titular de la Universidad Libre y la Escuela Superior de Administración Pública. Bogotá, Colombia. Contacto: willjime@esap.edu.co,gjimen00@gmail.com

***** Magíster en Filosofía de la Universidad Javeriana. Sociólogo y magíster en Sociología Política de la Universidad Nacional de Colombia. Docente investigador en la Facultad de Derecho de la Universidad La Gran Colombia. Bogotá, Colombia Contacto: omenesesq@ugc.edu.co

***** Recibido el 20 de julio de 2017, aprobado el 4 de abril de 2018.

Para citar el artículo: Leiva RamíReZ, E., Jiménez, W. G. y Meneses Quintana, O. Los derechos fundamentales de la Constitución Política de 1991 como resultado de un proceso constituyente deliberativo. En Revista Derecho del Estado, Universidad Externado de Colombia. N. 42 , enero-abril de 2019, pp. 149-180.

DOI: https://doi.org/10.18601/01229893.n42.06

****** Este documento es un avance de investigación de los proyectos de investigación "La Corte Constitucional y sus magistrados: 25 años de desarrollo constitucional colombiano para el mundo", perteneciente al grupo de investigación "Estado, Derecho y Territorio" de la Facultad de Derecho de la Universidad Libre; "Derecho e internet: jurisdicción y regulación jurídica en los casos de derecho a la intimidad versus derecho a la libertad de expresión", adscrito al grupo "Teoría del Derecho, de la Justicia y de la Política" de la Universidad La Gran Colombia; y "Legislación, Políticas Públicas y Democracia Deliberativa", adscrito al grupo de investigación "Estudios en Bioética, Ecología Humana y Ecología Política. Con(S)ciencia" de la Universidad Libre de Colombia. 
inclusión de principios democráticos que fundamentaran el Estado constitucional de derecho sobre el reconocimiento y respeto de la dignidad humana a través de una carta de derechos que cumpliría el rol de cláusulas contractuales vinculantes para los actores políticos que participaron en el proceso deliberativo constituyente de 1991. Este documento aborda los presupuestos fácticos que llevaron a la expedición de la Constitución Política de 1991 como un proceso democrático deliberativo, y los fundamentos políticos empleados para justificar su creación, especialmente el concepto de constituyente primario; así como las razones que le brindaron una esencia normativa a la consagración de una carta de derechos en la norma constitucional. Para ello, se expone inicialmente qué entiende la doctrina por proceso deliberativo; subsiguientemente se presentan sucintamente los hechos que antecedieron a la convocatoria a la Asamblea Nacional Constituyente para la modificación y posterior derogación de la Constitución Política de 1886; finalmente, se expone lo que el constituyente primario de 1991 pretendía con la consagración de un mínimo de derechos fundamentales según la jurisprudencia elaborada por la Corte Constitucional.

PALABRAS CLAVE

Poder constituyente, proceso deliberativo, Carta de Derechos Humanos, dignidad humana, pacto social.

\section{ABSTRACT}

The construction process of the Political Constitution of 1991 was a political response to complex social phenomena such as drug trafficking, political persecution social movements, and excessive use of the "state of siege". This led to various social movements seen in the structuring of a new political agreement a legitimate way to establish a democratic paradigm that will ensure respect for fundamental rights and the inclusion of democratic principles that would underpin the Rule of law on the recognition and respect of human dignity through a Bill of Rights that would fulfill the role of binding contractual clauses for political actors who participated in the 1991 constituent deliberative process. This document addresses the factual assumptions that led to the issuance of the Political Constitution of 1991 as a deliberative democratic process, and the political foundations used to justify its creation, especially the concept of primary constituent; and the reasons that led to giving the normative character to the consecration of a bill of rights in the constitutional norm. To do this, the doctrine will be initially explained by the deliberative process; Subsequently, the facts that preceded the convocation to an Asamblea Nacional Constituyente for the modification and subsequent repeal of the National Constitution of 1886 will be briefly 
explained to finally expose the role sought by the primary constituent of 1991 with the consecration of a minimum of fundamental rights according to the jurisprudence elaborated by the Constitutional Court.

\section{KEYWORDS}

Constituent power, deliberative process, Bill of Human Rights, human dignity, social pact.

\section{SUMARIO}

Introducción. 1. Procesos constituyentes en las democracias deliberativas. 2. Ejercicio del poder constituyente primario como proceso deliberativo. 3. La Constitución Política de 1991 como producto de un proceso deliberativo constituyente. 4. La Carta de Derechos como expresión del nuevo pacto político. Conclusiones. Referencias.

\section{INTRODUCCIÓN}

La historia constitucional de Colombia se caracteriza por los cambios constantes de sus ordenamientos constitucionales. Prueba de ello son las múltiples constituciones que se adoptaron entre 1811 y $1886^{[1]}$, esta última sometida a reformas en los años 1910, 1936, 1945, 1957 (mediante plebiscito), 1968, 1979 y 1986, y posteriormente derogada a finales del siglo. Por ello, el

1 "Antes de la Independencia definitiva del Virreinato de Nueva Granada en 1819, se conocieron distintas Constituciones denominadas como 'provinciales', siendo la primera la Constitución del Estado de Cundinamarca de 1811 y subsiguientemente la Constitución de Tunja de 1811 y la Constitución de Antioquia de 1811. En el año de 1812 se expidieron las Constituciones de la República de Cundinamarca y la del Estado de Cartagena. En 1815, fueron promulgadas la Constitución del Estado de Mariquita, la Constitución provisional de la Provincia de Antioquia y la Constitución de la Provincia de Neiva. Después de esto, se expidieron varias constituciones de carácter nacional, siendo la primera la Constitución de Cúcuta de 1821; la Constitución de 1830, la Constitución de 1832 o del Estado de Nueva Granada, la Constitución de 1843 o de la República de la Nueva Granada. Luego de estas, se expidieron unas Constituciones de tendencia federal, siendo la primera la Constitución de 1853, la Constitución de la Confederación Granadina de 1858. Véase Rodríguez, L. Derecho administrativo general y colombiano. Bogotá: Temis, 2013, 58 y la Constitución de los Estados Unidos de Colombia de 1863, en RESTREPO [PIEDRAhÍtA], C. Constituciones políticas nacionales de Colombia. Bogotá: Universidad Externado de Colombia, 1995, 10 y 11. Con la Constitución Política de 1886, se cerró la disputa entre centralismo y federalismo, primando totalmente la primera [sic], al punto que dicha concepción político-administrativa sigue plasmada en la Constitución Política de 1991[,] variándose en lo que hace relación a la autonomía territorial y administrativa[,] dando aplicación al concepto de centralización política y descentralización administrativa. La Constitución de 1886 fue sometida a reformas en los años de 1910, 1936, 1945, 1957 (mediante plebiscito), 1968, 1979 y 1986". LeIva, E. y MuÑoz, A. El poder constituyente y la Carta de Derechos en la Constitución Política de 1991. En Revista Administración \& Desarrollo. Vol. 39, n. ${ }^{\circ}$ 54. 2011, 119. 
proceso constituyente que culminó con la expedición de la Constitución de 1991 no debería ser considerado como extraordinario, pues lo usual hasta ese momento era resolver los conflictos políticos y sociales con la expedición de cartas políticas. Sin embargo, los hechos que motivaron a los movimientos sociales que presionaron para la expedición de la actual norma constitucional sí podrían ser considerados diferentes en comparación con los motivos de las anteriores cartas constitucionales ${ }^{2}$. Esta afirmación se fundamenta en dos presupuestos: el desconocimiento del procedimiento de reforma constitucional y el carácter deliberativo y pluralista que se presentó durante la creación de la Constitución actual.

El primer fundamento consiste en la no aplicación de las reglas de reforma constitucional establecidas en el año de 1957 y que prohibían modificar las disposiciones constitucionales por un mecanismo diferente al acto legislativo tramitado por el Congreso de la República ${ }^{3}$. El movimiento social que culminó con la creación de una asamblea nacional constituyente en 1990 se opuso a esta disposición normativa que impedía la reforma constitucional mediante asamblea, recurriendo al concepto de constituyente primario, lo que comportaba afirmar la necesidad de generar un proceso democrático para construir un acuerdo por determinación ciudadana, con todos los sectores de la sociedad, y lograr una Constitución concertada, y no impuesta luego de una victoria militar o política como ocurrió en los procesos constituyentes anteriores a la promulgación de la Constitución de 1991.

En cuanto al segundo fundamento, el proceso constituyente se caracterizó por su carácter deliberativo y pluralista, pues participaron la mayoría de las fuerzas políticas existentes en aquel momento a través de herramientas electorales (la votación de 1990 y la elección de los delegados a la Asamblea Constituyente) que legitimaron de una forma democrática las decisiones gubernamentales y judiciales que antecedieron a la promulgación de la Constitución actual. Ahora, la afirmación de que se trató de un proceso deliberativo se basa en que el proceso constituyente gozó de la participación de una pluralidad de corrientes ideológicas que previamente al proceso electoral adoptaron medios de expresión diferentes a los existentes normativamente, como fueron "La marcha del silencio", "la séptima papeleta" y la aproba-

2 Amador, S. El camino de la Constitución de 1991: diario de la exclusión. En Quintana, O. et al. Poder constituyente, conflicto y Constitución en Colombia. Bogotá: Universidad de los Andes, $2005,87$.

3 Constitución Política de 1886, art. 218: "La Constitución, salvo lo que en materia de votación ella dispone en otros artículos, sólo podrá' ser reformada por un Acto Legislativo, discutido primeramente y aprobado por el Congreso en sus sesiones ordinarias; publicado por el Gobierno, para su examen definitivo en la siguiente legislatura ordinaria; por ésta nuevamente debatido, y, últimamente, aprobado por la mayoría absoluta de los individuos que componen cada Cámara. Si el Gobierno no publicare oportunamente el proyecto de Acto Legislativo, lo hará el Presidente del Congreso". Este artículo fue incluido en la Constitución mediante el referéndum plebiscitario de 1957. 
ción por parte del Registrador Nacional del conteo de esta en las elecciones de 1990, entre otros espacios de diálogo que permitieron el intercambio de ideas y opiniones que se materializaron en la diversidad ideológica que representarían los delegados democráticamente elegidos para la Asamblea Nacional Constituyente ${ }^{4}$. Si bien los hechos que motivaron la creación de la Constitución Política de 1991 son diferentes a otros procesos de reforma constitucional, el instrumento que los actores consideraron apropiado para hacerle frente a la crisis institucional y social fue el mismo: la expedición de una nueva constitución ${ }^{5}$.

No obstante, el proceso constituyente que permitió la creación de la actual Constitución no puede ser considerado como un simple movimiento social. Al contrario, el ordenamiento constitucional vigente fue el producto de la necesidad de un nuevo marco jurídico-político que materializara un "pacto o contrato social" donde al Estado se le pudiese exigir no solo la garantía de la seguridad y la prestación de servicios públicos a los ciudadanos, sino la realización de un orden social más justo y equitativo que permitiera la construcción de una convivencia pacífica, en contraste con el infortunado estado de violencia que afrontaba la comunidad colombiana de finales del siglo xx. Si bien el nuevo pacto social no logró la materialización de una paz social ni acabó con la violencia, sí permitió la consagración de presupuestos normativos y acciones procesales que han permitido a lo largo de estos 27 años la materialización de los presupuestos del Estado social de derecho ${ }^{6}$,

4 Sobre la participación de estas corrientes sociales véase el título tercero de este documento.

5 Aunque la categoría de eficacia o uso simbólico del derecho no resulta metodológicamente aplicable al contexto que se está analizando en este acápite, sí es apropiado mencionar que los Estados de derecho de corte liberal confían en que las normas jurídicas (incluyendo las constitucionales) contribuyen a resolver los conflictos sociales por el efecto persuasivo que ellas poseen. Sobre el particular, García Villegas y Boaventura de Sousa sostienen: "Los gobiernos en Colombia intentan compensar la incapacidad del Estado para tratar las demandas sociales en términos políticos, con una fuerte insistencia en la dimensión jurídica de tales problemas [...] El déficit de maniobra política de los gobiernos propicia el uso simbólico de los discursos legales. Mientras más limitado es el margen de maniobra política de los gobiernos en Colombia y más incontrolable es la violencia, más inclinados están estos a tratar dichos problemas de manera tal que el énfasis institucional se ponga en la legitimación, la comunicación y el uso simbólico del derecho en la obtención de resultados". De Sousa Santos, B. y García Villegas, M. El caleidoscopio de las justicias en Colombia. Bogotá: Siglo xxi Editores, 2001, 73 y 74.

6 Aunque no es el referente jurisprudencial más próximo, la sentencia T-406 de 1992 permite visualizar las intenciones consagradas en la Constitución de 1991 y la forma como estas eran entendidas por los primeros intérpretes de esta norma jurídico-política:

"La fórmula del artículo primero de la Constitución, ampliada y respaldada a través de todo el texto fundamental, según la cual Colombia se define como un Estado social de derecho, es de una importancia sin precedentes en el contexto del constitucionalismo colombiano. Esta importancia amerita un pronunciamiento de la Corte sobre el alcance de este concepto y sobre su sentido e interpretación, no sólo en el contexto internacional -del cual sin duda alguna se nutrió la Asamblea Nacional Constituyente- sino en la Constitución misma, vista como una 
especialmente aquellos dirigidos a la eficacia de los acuerdos mínimos que están representados en la carta de derechos fundamentales, pues estos han sido una forma de limitar el ejercicio del poder público, evitando que este se desborde y vulnere el nuevo pacto social. El orden social e institucional que surgió con la Constitución de 1991 estaría determinado por la realización de los fines del Estado dentro de un marco de respeto de las garantías y derechos mínimos acordados y consagrados en el nuevo ordenamiento constitucional, es decir, "atado como Ulises al mástil para no sucumbir al canto de sirenas"

Este documento tiene como objetivo general analizar la expedición de la Constitución Política de 1991 como un proceso democrático deliberativo, los fundamentos políticos empleados para justificar su creación, especialmente el concepto de constituyente primario, y las razones que contribuyeron a darle carácter normativo a la consagración de una carta de derechos en la norma constitucional. Para ello, se describen los elementos propios de los procesos constituyentes en las democracias deliberativas; subsiguientemente se exponen de manera sucinta los hechos que antecedieron a la convocatoria de una asamblea nacional constituyente para la modificación y posterior derogación de la Constitución de 1886; y finalmente se estudia el propósito del constituyente primario de 1991 con la consagración de una carta de derechos fundamentales, teniendo como fundamento la jurisprudencia elaborada por la Corte Constitucional.

\section{PROCESOS CONSTITUYENTES EN LAS DEMOCRACIAS DELIBERATIVAS}

Existen posturas que privilegian los aspectos formales de la democracia (elecciones libres, libertad de expresión, rendición de cuentas por parte de las autoridades públicas, etc.) sobre los sustanciales. "Prueba de ello son los argumentos de algunos iusfilósofos que conciben la democracia como un conjunto de reglas y procedimientos para someter determinadas decisiones a la mayoría". Sin embargo, la anterior postura resulta insuficiente, pues la democracia, más que una forma de gobierno, es una vivencia de la políti-

norma autónoma [...] El Estado constitucional democrático ha sido la respuesta jurídico-política derivada de la actividad intervencionista del Estado. Dicha respuesta está fundada en nuevos valores-derechos consagrados por la segunda y tercera generación de derechos humanos y se manifiesta institucionalmente a través de la creación de mecanismos de democracia participativa, de control político y jurídico en el ejercicio del poder y sobre todo, a través de la consagración de un catálogo de principios y de derechos fundamentales que inspiran toda la interpretación y el funcionamiento de la organización política". Corte Constitucional. Sentencia T-406 de 1992, M.P.: Ciro Angarita Barón.

7 ELSTER, J. Ulises desatado: estudios sobre racionalidad, precompromiso y restricciones. Barcelona: Gedisa, 2002, 67.

8 LeIVA, E. La influencia de las Tic y la educación cívica en los procesos deliberativos de las sociedades pluralistas. En Revista de Derecho, Comunicaciones y Nuevas Tecnologías. N. ${ }^{\circ} 14,3$. 
$\mathrm{ca}^{9}$. Por ello, los conceptualismos generados por la formalidad jurídica y la economía son ajenos a la mayoría de los ciudadanos ${ }^{10}$, aspecto que motiva a la elaboración de conceptos que permitan materializar y vivenciar los principios y valores consagrados en las cartas de derechos tan en boga a partir de la segunda década del siglo xx como una forma de materializar los acuerdos políticos que surgen de procesos democráticos ${ }^{11}$. Por ejemplo, el garantismo jurídico propone dos visiones sobre la democracia: una formal -relativa a los procedimientos-y otra sustancial -concerniente a los derechos fundamentales que el Estado tiene el deber de garantizar- ${ }^{12}$. Igualmente, un sector del neoconstitucionalismo intenta recuperar el fundamento de las cartas de derechos a través de la superación de los modelos formalistas que legitimaban el Estado de derecho ${ }^{13}$. Con un enfoque distinto, pero no contradictorio, existen posturas que consideran que el proceso deliberativo requiere de un conocimiento sobre lo que es la democracia, para que esta sea activa y no meramente formal ${ }^{14}$, haciendo de las democracias modernas procesos deliberativos de ciudadanos conscientes de sus derechos y garantías constitucionales ${ }^{15}$.

$9 \quad$ Ibíd., 3.

10 HABERMAS, J. Teoría de la acción de la acción comunicativa: racionalidad de la acción y racionalización social. Madrid: Taurus, 1987, 210.

11 LeIva. La influencia de las Tic y la educación cívica en los procesos deliberativos de las sociedades pluralistas, cit., 5 .

12 Ferrajoli, L. Principia iuris: teoría del derecho y de la democracia. Madrid: Trotta, 2011, 90 .

13 PRIETO, L. Derechos fundamentales neoconstitucionalismo y ponderación judicial. Lima: Palestra, 2002, 81.

14 De esta forma, el derecho a la educación adquiere un carácter político, pues a través de él la ciudadanía puede adquirir no solo conocimientos académicos, sino aquellos de contenido democrático, permitiendo estos últimos el ejercicio de las garantías constitucionales que contribuyen a la realización de una constitución viviente. WALUCHOW, W. Una teoría del control judicial de constitucionalidad basada en el commom law: un árbol vivo. Madrid: Marcial Pons, 2009,350 .

15 "Junto a los tradicionales derechos de libertad, las Constituciones de este siglo han reconocido sin embargo otros derechos vitales o fundamentales: los ya recordados derechos a la subsistencia, a la alimentación, al trabajo, a la salud, a la educación, a la vivienda, a la información y similares. A diferencia de los derechos de libertad, que son derechos (o facultades de comportamientos propios) a los que corresponden prohibiciones (o deberes públicos de no hacer), estos derechos, que podemos llamar 'sociales'o también 'materiales', son derechos (o expectativas de comportamientos ajenos) a los que deberían corresponder obligaciones (o deberes públicos de hacer). La noción liberal del ‘estado de derecho' debe ser, en consecuencia, ampliada para incluir también la figura del estado vinculado por obligaciones además de por prohibiciones. Diremos por consiguiente que cuando un ordenamiento constitucional incorpora sólo prohibiciones, que requieren prestaciones negativas en garantía de los derechos de libertad, se le caracteriza como estado de derecho liberal; cuando por el contrario incorpora también obligaciones, que requieren prestaciones positivas en garantía de derechos sociales, se le caracterizará como estado de derecho social”. FerRajoli, L. Derecho y razón: teoría del garantismo penal. Madrid: Trotta, 1995, 861. 
Ahora bien, el conocimiento de los presupuestos constitucionales puede generar una ciudadanía deliberativa, consciente de su destino político, y, por ende, la creación de espacios para ejercer sus derechos. Así, Martí plantea que una sociedad deliberativa real debe "tomar medidas de educación y formación de la ciudadanía en tales virtudes públicas y diseñar mecanismos de participación política que contemplen la posibilidad de que muchos de los participantes puedan ser virtuosos e incentiven la virtud de la ciudadanía" ${ }^{16}$. Por esta razón, la educación cívica permite la comunicación de los presupuestos democráticos de una sociedad políticamente activa. Sobre este aspecto, Habermas plantea que todo lo que tiene validez se tiene que justificar públicamente ${ }^{17}$. En efecto, "la democracia deliberativa considera la determinación democrática -los espacios privados y públicos de la vida en común-, como una cuestión que solo es posible solventar a través de la deliberación o la discusión pública abierta a todos los participantes en la sociedad democrática"18.

La discusión o deliberación pública democrática no puede tener vedado ningún tema ni ninguna forma de entender el bien social, ni negar espacios de interacción entre los actores, pues de esta forma es posible ir vivificando los valores democráticos e ir construyendo parámetros de legitimidad para exigir al Estado la protección de los derechos fundamentales consagrados en las disposiciones constitucionales, o bien de aquellos que, sin estar expresamente reconocidos por los ordenamientos jurídicos internos, hacen parte del derecho internacional de los derechos humanos.

Los espacios para el ejercicio de estos procesos deliberativos son esenciales, y estos a su vez pueden categorizarse en vías institucionales y no institucionales. Los primeros son aquellos que se desarrollan en el marco de un proceso decisorio legalmente establecido y regulado, y que conducirá a tomar algún tipo de decisión jurídica en sentido amplio. Los segundos son los que se desarrollan amplia, difusa e informalmente en múltiples espacios y contextos de la esfera pública, que no están jurídicamente establecidos y no desencadenan una decisión jurídica ${ }^{19}$. "Las democracias deliberativas re-

16 Martí, J. La república deliberativa: una teoría de la democracia. Madrid: Gedisa, 2006, 297.

17 Habermas. Teoría de la acción de la acción comunicativa: racionalidad de la acción y racionalización social, cit., 360 .

18 LeIva. La influencia de las Tic y la educación cívica en los procesos deliberativos de las sociedades pluralistas, cit., 7.

19 Sobre el particular, Martí afirma: "Los procesos deliberativos institucionales se regulan mediante derechos y obligaciones establecidos por otras normas jurídicas, y además están vinculados a los poderes del Estado. Los procesos deliberativos no institucionales, por su parte, son procesos difusos, mucho más complejos y no reglamentados directamente por una norma jurídica, que tienen lugar en la esfera de la sociedad civil, con diferentes estructuras más o menos establecidas, diversa intensidad e importancia, etc., como la publicación de artículos de opinión, cartas al director en la prensa, los debates televisivos, las conversaciones de café, etc. En estos 
quieren de estos espacios no institucionales, pues estos fortalecen el debate público y contribuyen a un cambio de paradigma de democracia representativa a uno de democracia directa" 20 .

Así las cosas, la afirmación en el sentido de que el proceso constituyente que conduce a la creación de la Constitución de 1991 no puede ser considerado contrario a una democracia deliberativa, así este no hubiese sido según los parámetros institucionales consagrados en la Constitución de 1886. Ahora bien, las decisiones de la Corte Suprema de Justicia en desarrollo de sus competencias avalaron los diferentes actos que permitieron la convocatoria para la elección de los delegados a la Asamblea Nacional Constituyente, y los marcos de su competencia, ello no significa que el argumento adoptado fuese producto de un estudio exegético de las normas jurídicas vigentes en aquel momento. En efecto, era más bien el resultado de una interpretación axiológica de los principios constitucionales atendiendo al concepto de poder constituyente primario, pues este no se somete a los límites del orden institucional establecido, aunque sí se encuentra restringido al respeto de los principios de los sistemas democráticos, como el principio de la dignidad y el de la separación del poder público ${ }^{21}$. Por ello, las decisiones adoptadas por la Corte Suprema de Justicia fueron extraconstitucionales, pero no inconstitucionales ${ }^{22}$. Del papel del poder constituyente primario como reflejo de los procesos deliberativos no institucionales se trata a continuación.

\section{EJERCICIO DEL PODER CONSTITUYENTE PRIMARIO COMO PROCESO DELIBERATIVO}

La teoría de la soberanía popular conduce a la reflexión acerca de la teoría del poder constituyente, comoquiera que esta representa una manifestación de aquella ${ }^{23}$. Por ello, la doctrina y la jurisprudencia constitucionales consideran que en Colombia la democracia se ha manifestado de dos formas: directamente ${ }^{24}$

casos, no es posible determinar institucionalmente quién debe deliberar, así que los sujetos de la deliberación son potencialmente todos los seres humanos". MARTí. La república deliberativa: una teoría de la democracia, cit., 80.

20 LeIVA. La influencia de las Tic y la educación cívica en los procesos deliberativos de las sociedades pluralistas, cit., 6 .

21 Corte Constitucional. Sentencia C-141 de 2010, M.P.: Humberto Antonio Sierra Porto.

22 Sobre el análisis realizado por la Corte Suprema de Justicia y las sentencias de constitucionalidad a los decretos que convocaban a una Asamblea Nacional Constituyente, véase el título III de este documento.

23 Corte Constitucional. Auto A003 de 1992, M.P.: Alejandro Martínez Caballero.

24 Entre los ejemplos de este tipo de actividad política se encuentran el plebiscito de 1957 o a través de comisionados por el pueblo para una asamblea constituyente. En 1863 y 1886 la Asamblea fue producto de la decisión de los triunfadores de una guerra civil. Y en 1991 fue producto del sufragio universal, igual y secreto como procedimiento democrático. En estos casos no existen otros límites que los que el pueblo haya establecido. Estos comisionados disponen de todos los medios para cumplir un fin. 
o por representación ${ }^{25}$. En lo que respecta a la teoría constitucional, la primera es el fundamento del concepto de poder constituyente en sentido estricto, o poder constituyente primario u originario, y la segunda es una de las bases del poder de reforma, o poder constituyente derivado o secundario ${ }^{26}$. El primero está radicado en el conjunto de personas organizadas políticamente y que tienen y conservan la potestad de darse una constitución. Este poder constituyente originario no está entonces sujeto a límites jurídicos del orden normativo vigente, y comporta un ejercicio pleno del poder político de los asociados ${ }^{27}$. En otro sentido, el poder de reforma o poder constituyente derivado se refiere a la capacidad que tienen ciertos órganos del Estado de modificar una constitución existente, pero dentro de los cauces determinados por esta. Esto significa que se trata de un poder establecido por la constitución, y que se ejerce de acuerdo con las condiciones fijadas por ella misma, como son los criterios de competencia, procedimientos, etc. Se trata, por lo tanto, de un poder de reforma de la propia constitución, y en ese sentido es constituyente, pero con límites y sujeto a controles ${ }^{28}$.

25 "Un simple repaso de nuestra historia constitucional y política es el mejor medio demostrativo de lo afirmado. En las incipientes e inestables formas políticas de la sociedad colombiana en el siglo XIX, el constituyente primario está plenamente ausente de las constituciones de Cúcuta, Ocaña, Rionegro y hasta de la de Núñez y Caro, vigente durante casi todo el xx; pues aun cuando para la adopción de esta última se acudió a un consejo de delegatarios, que actuó como cuerpo constituyente, su origen no fue más allá del querer del Regenerador.

"Similares consideraciones pueden hacerse respecto de la única intervención popular en materia constitucional en el siglo anterior, pues de todos son conocidas las circunstancias que rodearon el acto plebiscitario de diciembre de 1957, muy alejadas de lo que pudiera llamarse una verdadera manifestación libre, espontánea y soberana de la mayoría de la población". MonCAYo, V. El Leviatán derrotado: reflexiones sobre teoría del Estado y el caso colombiano. Bogotá: Norma, 2004, 281.

26 "De conformidad con la doctrina universal de la teoría general del Estado, en la democracia constitucional el poder soberano del pueblo se ejerce de dos maneras diferentes:

"- Como un poder pleno, soberano en sentido lato, cuando se manifiesta en las circunstancias propias de la creación de una constitución.

“- Como un poder velado pero potencial, cuando se ejerce durante la vigencia y eficacia de una constitución. En este caso el poder soberano se encuentra encauzado por los parámetros constitucionales y sólo se manifiesta directamente cuando se produce una crisis constitucional que ponga en duda la validez o la eficacia de la constitución”. LeIVA y MuÑoz. El poder constituyente y la Carta de Derechos en la Constitución Política de 1991, cit., 120.

27 "El poder constituyente es el pueblo, el cual posee per se un poder soberano absoluto, ilimitado, permanente, sin límites y sin control jurisdiccional, pues sus actos son políticos-fundacionales y no jurídicos, y cuya validez se deriva de la propia voluntad política de la sociedad. Casi siempre su manifestación va acompañada de una ruptura del orden jurídico anterior. El poder del pueblo es anterior al derecho, fuente del derecho, esencia del derecho y modificatorio de todo el derecho, inclusive el derecho constitucional". Corte Constitucional. Auto A003 de 1992, M.P.: Alejandro Martínez Caballero.

28 "Así, en el caso colombiano, los artículos 374 y siguientes de la Constitución establecen e instituyen ese poder de reforma, pues regulan los modos de reforma de la Carta, que son: acto legislativo, referendo y Asamblea Constituyente. Esas normas fijan además las reglas y los procedimientos a los cuales están sometidos tales mecanismos de reforma constitucional. Así 
Durante la vigencia de una constitución, el pueblo como constituyente primario se encuentra en un estado de latencia y solo se manifiesta directamente cuando se produzca una crisis institucional que ponga en duda la validez o la eficacia de la constitución. En tales circunstancias, el pueblo puede reasumir su potestad soberana, caso en el cual se produce una ruptura del orden establecido y hay lugar a un nuevo acto fundacional ${ }^{29}$. "Pero en condiciones de normalidad, el poder del pueblo se encuentra encauzado por parámetros constitucionales, esto es, constituido por las normas superiores que fijan las condiciones para su ejercicio" 30 .

$\mathrm{El}$ anterior argumento demuestra que el acto del constituyente primario trasciende la mera adopción verbal o escrita de una constitución, pues la manifestación de esta voluntad popular incorpora factores determinantes de un orden político-jurídico, como la estructura del poder estatal, las relaciones entre el Estado y el resto de la sociedad, los deberes estatales y los derechos y deberes de los particulares, los mecanismos de solución de conflictos y la manera de proteger el esquema adoptado. Estos factores son lo que delimita el ejercicio del poder constituido (que incluye el poder de reforma de la constitución), pues "este únicamente tiene existencia a partir del hecho constituyente y en los términos definidos por las decisiones fundamentales tomadas por el poder constituyente" ${ }^{31}$. Por esta razón, el poder constituyente derivado no tiene competencia para destruir la constitución, pues cualquier poder de reforma que el constituyente primario reconozca únicamente se limita a una revisión; es decir, el poder constituido no puede arrogarse funciones

las cosas, no duda la Corte que en tales eventos se está frente al ejercicio de un poder derivado y, por lo mismo, limitado por la propia Constitución”. Corte Constitucional. Sentencia C-551 de 2003, M.P.: Eduardo Montealegre Lynett.

29 "En pocas pero trascendentes palabras, el poder constituyente primario representa una potencia moral y política de última instancia, capaz aun en las horas de mayor tiniebla, de fijar el curso histórico del Estado, insurgiendo [sic] como tal con toda su esencia y vigor creativos.

"Por esto mismo, sabe abrir canales obstruidos de expresión, o establecer los que han sido negados, o, en fin, convertir en eficaz un sistema inidóneo que, por factores diversos, ha llegado a perder vitalidad y aceptación". Younes Moreno, D. Panorama de las reformas del Estado y de la Administración Pública. Bogotá: Universidad del Rosario, 2004, 196.

30 LeIva y MuÑoz. El poder constituyente y la Carta de Derechos en la Constitución Politica de 1991, cit., 121. Ha dicho, por su parte, la Corte Constitucional: "De este modo, una es la situación cuando el pueblo, en un acto de auto afirmación y por fuera de todo cauce normativo, decide reformar la Constitución o darse una nueva, y establece para ello los mecanismos que resulten apropiados, y otra muy distinta aquella en la cual, a la luz de las previsiones constitucionales, el pueblo es convocado para que decida si convoca una asamblea nacional constituyente con el periodo y las competencias que el Congreso, órgano constituido, le haya fijado en una ley, o cuando, también mediante ley, se le convoca para que exprese su afirmación o su negación a una propuesta de reforma a la Constitución. En el primer caso el pueblo actúa como constituyente primario, en el segundo obra en el ámbito de los poderes constituidos y se encuentra subordinado a la Constitución". Corte Constitucional. Sentencia C-180 de 2007, M.P.: Rodrigo Escobar Gil.

31 Corte Constitucional. Sentencia C-551 de 2003, M.P.: Eduardo Montealegre Lynett. 
propias del poder constituyente originario, pues de ser así estaría realizando una sustitución de la constitución, no solo porque se estaría erigiendo como poder constituyente primario sino también porque estaría minando las bases de su propia competencia.

La precedente afirmación remite a uno de los problemas más complejos de la teoría y la práctica constitucionales: ¿cuál es el papel del pueblo, como poder constituyente originario y depositario de la soberanía una vez que este se ha dictado la constitución? Una respuesta a este interrogante puede encontrarse en los mecanismos de reforma constitucional consagrados en la norma constitucional. En efecto, el poder de revisión o modificación constitucional no es obra del poder constituyente originario ni del pueblo soberano, sino que es expresión de una competencia jurídicamente organizada por la propia constitución y limitado por la imposibilidad de sustituir las disposiciones constitucionales; de lo contrario, el poder de reforma se erigiría en poder constituyente primario ${ }^{32}$.

La fijación de un cauce al poder constituyente originario es siempre imperfecta, pues el poder constituyente, por sus propias características, es rebelde a una integración total en un sistema de normas y competencias, y por ello no admite una institucionalización total. No obstante, ese direccionamiento existe gracias a la inclusión de presupuestos axiológicos en las sociedades democrática que relativizan la original naturaleza de absoluto que tenía el ejercicio del poder constituyente primario. De esta forma, la expresión del constituyente originario se somete a estas posturas axiológicas que van a permitir que el ejercicio de esta potestad no ocasione innecesarias rupturas institucionales ${ }^{33}$. Por lo anterior, cuando una sociedad políticamente organizada escoge un modelo de democracia constitucional está aceptando que todo ejercicio del poder debe tener límites y, por lo tanto, como pueblo soberano acuerda constituirse y autolimitarse de conformidad con ese modelo democrático, instituyendo cauces a través de los cuales pueda expresarse en cualquier escenario deliberativo. Sin embargo, la Corte Constitucional ha

32 "El problema surge entonces cuando la ciudadanía manifiesta claramente su voluntad de sustituir la Carta. En tales eventos, si la propia Constitución no prevé alguna forma de expresión jurídica del poder constituyente originario, entonces se llega al siguiente dilema indeseable: o la dinámica del poder constituyente se ve obstruida y asfixiada por los límites al poder de reforma; o por el contrario, una ruptura constitucional ocurre a fin de permitir la expresión del poder constituyente". Corte Constitucional. Sentencia C-551 de 2003, M.P.: Eduardo Montealegre Lynett.

33 "La idea de pueblo soberano es un concepto constitucional límite estrechamente relacionado con las ideas de soberanía, democracia liberal y democracia constitucional. La visión histórica y conceptual típica del Estado liberal de derecho que predominó desde el siglo XVIII, propugnó una noción de soberanía enmarcada dentro del concepto de nación como unidad homogénea. A partir de la Segunda Guerra Mundial esa noción decimonónica ha evolucionado hacia una visión pluralista, de acuerdo con la cual es menester garantizar tanto la posición de la mayoría como las voces de las minorías y ya no es posible que un único grupo de ciudadanos, por numeroso y respetable que sea, se atribuya la voz del pueblo soberano". Corte Constitucional. Sentencia C-141 de 2010, M.P.: Humberto Antonio Sierra Porto. 
estimado que la Constitución de 1991 intenta superar este dilema y la tensión entre la soberanía popular y la supremacía constitucional por medio de una apertura al poder constituyente originario, previendo un procedimiento agravado de reforma. Prueba de ello es lo consagrado en la sentencia C-1040 de 2005. En esta providencia se estableció que "el pueblo puede investir a una Asamblea Constituyente de la competencia para expedir una nueva Constitución, posibilidad expresamente permitida en el artículo 376 de la Carta”, y que "sólo por medio de este mecanismo puede ser sustituida la Constitución vigente por una opuesta o integralmente diferente" ${ }^{34}$. En esta hipótesis el pueblo, todavía como poder constituido, decide si convoca o no la asamblea $\mathrm{y}$, al definir su competencia, puede otorgarla para una simple reforma, propia del poder constituido, o concederle facultades tan amplias que su ejercicio conduzca al cambio de la constitución vigente por otra, siempre que el mismo pueblo, al fijar la respectiva agenda, así lo haya determinado ${ }^{35}$. Este supuesto no hace desaparecer del todo los límites pues, aunque ya no provendrían de lo dispuesto en la constitución sustituida, tendrían su origen en las normas imperativas de derecho internacional y también en los convenios internacionales de derechos humanos ${ }^{36}$, para citar apenas dos ejemplos.

34 Sin embargo, el título XIII y el artículo 374 se refieren únicamente a "reforma"; es desacertado lo señalado en dicha sentencia, pues es lógico que la misma Constitución solo prevea su reforma, no su sustitución, puesto que esta última es un acto autónomo del poder constituyente primario, que no necesita ser regulado.

35 "El razonamiento político-jurídico que se esgrime es irrebatible. El mandante primario, que da origen a la Asamblea, no puede tener limitaciones surgidas de delegados. De este modo, se ratifica el carácter de poder primario de la Constituyente y se zanja [sic] las disputas acerca de los límites atribuibles a su naturaleza “derivada"”. Verdesoto, L. Procesos constituyentes y reforma institucional: nociones para comprender y actuar en el caso ecuatoriano. Quito: AbyaYala, 2007, 121.

36 Este presupuesto de limitación del poder constituyente primario viene a ser confirmado en la sentencia C-141 de 2010. En efecto, esta providencia judicial consagra las limitaciones axiológicas y de normatividad internacional a las cuales se encuentra sometido el ejercicio de ese poder: "Así pues, de los distintos mecanismos contemplados en el artículo 374 constitucional el único que no está sujeto a límites de competencia es una Asamblea Nacional Constituyente, siempre que sea convocada expresamente para proferir una nueva Carta.

"Considerar sistemáticamente que una decisión del pueblo que interviene por fuera de las formas prescritas legitima un procedimiento de revisión constitucional 'ilícito', equivaldría a introducir un procedimiento débil de revisión constitucional al lado del estricto normal. Ahora bien, la rigidez y la dificultad de un procedimiento permiten preservar las reglas fundamentales establecidas en la Constitución y garantizan la seguridad jurídica. Una Constitución establece un sistema equilibrado y elaborado luego de una reflexión madura. La intervención del pueblo por fuera de toda forma podría destruir este equilibrio por la vía de un simple voto emitido por la pasión del momento. Ello no es una garantía para la supervivencia de la democracia y del Estado de derecho, pues el iniciador del voto tiene allí un formidable poder de destrucción del orden establecido [...] La decisión popular ha sido considerada como justa y sabia y el principio de soberanía del pueblo conoce sus horas de gloria. Sin embargo, en nuestros días, este último no puede ser concebido como un poder absoluto e ilimitado, a punto que permita al pueblo actuar de forma arbitraria. Dicho principio se debe conciliar con otros principios, específicamente el 
En consecuencia, la intangibilidad de la constitución no es un golpe de Estado ni la apertura de una brecha en el Estado de derecho, pues si el constituyente primario es capaz de adoptar una nueva constitución aun en contra de la anterior, como en efecto ocurrió en el caso de la de 1991, a fortiori puede en todo momento establecer cláusulas que garanticen la estabilidad del nuevo ordenamiento, máxime cuando este es de carácter democrático y humanista ${ }^{37}$. Si bien, el texto constitucional colombiano no establece cláusulas pétreas ni principios intangibles, tampoco autoriza expresamente la sustitución integral de la Constitución, pues si esto fuese posible la Asamblea Constituyente hubiera incorporado esa posibilidad de cambio total o reforma integral, como lo hacen expresamente otros ordenamientos constitucionales ${ }^{38}$. Por esta razón, el poder de reforma constitucional en el Estado colombiano tiene límites competenciales establecidos en el artículo 374 de la Constitución adoptada en 1991 por la Asamblea Constituyente como comisionada del pueblo soberano (constituyente primario), y que consagró para proteger la identidad y continuidad de la nueva carta; sin que esto significara una intención de petrificar el texto constitucional, sino una forma de "blindar" un orden democrático deliberativo y participativo contrario al existente antes

del respeto de la 'legalidad' en sentido amplio. Como lo anota M. Luciani, 'la observancia de las formas, el respeto de la legalidad es hoy en día [...] un elemento esencial de la legitimidad. Las teorías democráticas más maduras y más elaboradas no se contentan con un poder sólidamente legítimo, sino que observan el corazón de la democracia en el hecho de que este poder sea al mismo tiempo limitado. Y la limitación se encuentra sobre todo en el respeto de las formas, de las reglas, en una palabra, de la legalidad"'.

37 La sentencia C-544 de 1992 trae unas frases contundentes en relación con los conceptos intangibles que posee la Constitución Política de 1991: "Queda así en firme la Constitución Política de Colombia de 1991 como expresión de la voluntad política del pueblo colombiano y su texto actual no es susceptible de ser demandado.

"De esta manera se recoge la voluntad del Constituyente y se sienta un principio de seguridad jurídica indispensable para el orden normativo de la República”.

38 "En Colombia dicho concepto no es desconocido por el ordenamiento constitucional. La Constitución de Cúcuta de 1821 establecía el término de diez (10) años para que esta pudiera ser reformada. Sin embargo, esta cláusula, fue desconocida por el 'Congreso Admirable' con la promulgación el 29 de abril de 1830 de una nueva Constitución.

"En el derecho comparado contemporáneo, la finalidad de una constitución tiene también carácter intangible. Es el caso de Alemania, donde el numeral 3 del artículo 79 dice: 'Es inadmisible toda modificación de la presente Ley Fundamental que afecte. En la Constitución Nacional española el artículo 168 establece así mismo un procedimiento calificado para reformar los temas que tratan el fundamento del Estado. En la Disposición Final Transitoria No. 12 de la Constitución Italiana se hace lo propio. Otros textos constitucionales, también han previsto esa posibilidad, como la Constitución francesa de 1848, la Constitución de Suiza, la Constitución argentina de 1853 o la Constitución de Venezuela, que establece un determinado procedimiento para las reformas y enmiendas parciales, mientras que para la adopción de una nueva Constitución exige la convocatoria a una asamblea constituyente". LEIVA y MuÑOZ. El poder constituyente y la Carta de Derechos en la Constitución Política de 1991, cit., 121. 
de 1991 y que se caracterizaba por el carácter intangible y restrictivo del artículo 218 de la Constitución de $1886^{[39]}$.

A continuación se procede a realizar una descripción de los antecedentes que llevaron a la concretización de la voluntad del constituyente primario en la Constitución Política de 1991.

\section{LA CONSTITUCIÓN POLÍTICA DE 1991 COMO PRODUCTO DE UN PROCESO DELIBERATIVO CONSTITUYENTE}

La compleja coyuntura social, económica y política que existió durante el proceso de gestación de la Constitución de 1991 es un elemento indispensable para comprender las razones que llevaron al movimiento social de inicios de 1990 a impulsar la adopción de una norma constitucional que derogara la de 1886. Esta coyuntura puede ser vista atendiendo, en general, a las transformaciones y/o situaciones que afrontaban las naciones latinoamericanas, que vieron en la modificación de sus ordenamientos constitucionales una forma de adaptarse a los cambios surgidos de la globalización; así como, en particular, a la necesidad de superar la patológica violencia y el caos institucional que se vivían en la sociedad colombiana ${ }^{40}$.

39 La Corte Constitucional consideró que el movimiento social que llevó a la creación de un nuevo orden institucional fue el producto de la imposibilidad de hacer cambios constitucionales por los mecanismos establecidos por el régimen normativo vigente en aquel momento, situación que le da un carácter de validez y legitimidad al proceso constituyente que llevó a la creación de la Constitución Política de 1991: "En el proceso de reforma institucional vivido por Colombia en 1990-1991, el pueblo se expresó por un procedimiento adecuado, en medio de una crisis constitucional". Corte Constitucional. Sentencia C-544 de 1992, M.P.: Alejandro Martínez Caballero.

40 "La convocatoria a una Asamblea Constituyente no es un procedimiento nuevo. Se han utilizado en diversos países durante los siglos XIX y Xx. En Perú se recurrió a la Asamblea Constituyente para elaborar su Constitución de 1979. Es a partir de la salida del régimen militar en Brasil cuando el llamamiento a Asambleas Constituyentes se va a generalizar en América Latina como el procedimiento más idóneo de refundación del Estado mediante un acto constituyente de amplio compromiso popular. En 1987 se reúne en Brasilia la ANC, a la que el Gobierno brasileño de la época pretende limitar sus poderes, pero la movilización social que desencadenó hasta presentarse sesenta y una mil enmiendas al texto constitucional, convirtió a esta Asamblea en un órgano soberano pleno. La Constitución brasileña de 1988 es la obra fundamental de la Constituyente $[\ldots]$

"La reforma constitucional en Argentina de 1994, se planteó como un acuerdo del Congreso para convocar una Convención reformadora, que si no introdujo novedades importantes, suponía una ruptura de la doctrina tradicional, según la cual sólo el Congreso tenía capacidad reformadora. En Venezuela se plantea tras las elecciones presidenciales de 1993 la posibilidad de que el Congreso, elegido ese año, actúe como Congreso Constituyente, sobre la base del Proyecto de la llamada Comisión Bilateral. Sin embargo, fue con la victoria del entonces candidato del Polo Patriótico, Hugo Chávez Frías (cuya propuesta política principal era la convocatoria de la Asamblea Nacional Constituyente) que se convocó a una ANC y se elaboró la Constitución de 1999". Colomer, A. Comunidades y ciudades, constituciones y solidaridades. Valencia: Universidad Politécnica de Valencia, 2007, 56 a 58. 
Respecto de las primeras, Latinoamérica se suscribía por entonces a un nuevo modelo económico que exigía modificaciones estructurales dirigidas a permitir la inclusión de políticas de apertura económica y la contracción del papel del Estado ${ }^{41}$; es decir, una profunda modificación del modelo intervencionista implementado durante los gobiernos liberales de la década de 1930, a favor del modelo económico neoliberal del llamado Consenso de Washington $(1989)^{42}$. En lo referente al contexto social colombiano, el proceso constituyente se gestó dentro de una coyuntura de crisis, y bajo la creencia de que con la expedición de una nueva carta política era posible conjurarla ${ }^{43}$ o, cuando menos, paliarla ${ }^{44}$. En efecto, los referentes reformistas más próxi-

41 "Las experiencias de las Asambleas Constituyentes en América Latina y en particular en los países andinos, permiten obtener algunas conclusiones. Miradas desde sus resultados, las Asambleas no han ejercido ni traducido la totalidad o la potencialidad del concepto de "poder constituyente' que las anima. Esto es, no han producido una re-fundación de todos los ámbitos del poder público. Más bien se han aproximado a una re-estructuración jurídica, a escala constitucional, más o menos general de las instituciones estatales y sociales. En corto, las Asambleas se han circunscrito al ámbito de la reforma 'total' de la Constitución, cuya profundidad y alcance en la coyuntura de cada país". Verdesoto. Procesos constituyentes y reforma institucional: nociones para comprender y actuar en el caso ecuatoriano, cit., 120.

42 "Las prescripciones del Consenso de Washington que se tradujeron en las políticas neoliberales de los noventa impulsadas por el Banco Mundial y el Fondo Monetario Internacional en los países en vía de desarrollo fueron replicadas [en la Constitución de 1991]. Aunque la intervención del Estado en los derechos de propiedad debería ser mínima, en caso de reglamentación alguna, esta debería hacerse para garantizar la propiedad de los inversionistas o empresarios. Lo importante era la protección del capital privado mediante normas y políticas públicas que garantizaran los derechos de primera generación". AlVIAR, H. y VILlEgAS, C. La función social de la propiedad en las constituciones colombianas. Bogotá: Universidad de los Andes, 2012, 53. Igualmente, César Rodríguez considera que estas políticas desarrollaron reformas orientadas a la disciplina fiscal, la reducción y reorientación del gasto público, la reforma fiscal para ampliar la base tributaria, la liberación financiera, la libre flotación de la tasa de cambio, la reducción de aranceles, la eliminación de las barreras a la inversión extranjera directa, la privatización de las empresas de propiedad estatal, el desarrollo de la competencia dentro del mercado y la existencia de derechos de propiedad seguros. RodríGuez, C. La globalización del Estado de derecho. Bogotá: Universidad de los Andes, 2009, 25.

43 "La gran sensación de crisis y ansiedad que de forma imparable se fue apoderando del gobierno de Barco y de la sociedad colombiana en general, fue parcialmente paliada con la iniciativa de reformar el maderamen ya centenario de la Constitución de 1886. La vieja práctica fetichista de intentar reformar realidades con el simple cambio de normas escritas alimentó más de una iniciativa de referendo constitucional, mientras que para el país resultaba cada vez más claro que la bienvenida a la década de los noventa no traería consigo el desmantelamiento de los carteles de la droga, la neutralización de los grupos paramilitares ni la desarticulación del longevo problema guerrillero. Por su parte, parcialmente estacionada en arenas distintas a las de los sectores políticos y gubernamentales tradicionales, empezó a tomar fuerza inusitada la invitación de distintas expresiones del ámbito estudiantil de emprender una reforma radical e inmediata a la Constitución de 1886 . Su cenit tendría lugar con la incorporación y exitosa votación de la llamada séptima papeleta, cuyo mandato legitimó la convocatoria a la tantas veces invocada Asamblea Constituyente". B ARRETO, A. La generación del estado de sitio. Bogotá: Universidad de los Andes, 2011, 73.

44 "Tres problemas centrales existían en Colombia en el momento en que sale a la luz 
mos al proceso constituyente de 1991 son los actos legislativos 02 de 1977 y 01 de 1979 (en los que se propuso convocar una asamblea constitucional), reformas que resultaron fallidas al ser declarados inexequibles por la Corte Suprema de Justicia, en 1978 y 1981 respectivamente. Dicha Corte, quien para ese entonces desempeñaba también el control constitucional, cerró las puertas a esas dos iniciativas al encontrar vicios de procedimiento y de fondo, a partir de un análisis riguroso y exegético. Si a lo anterior se suman los frustrados intentos de reforma constitucional del Gobierno de Barco (1986-1990), el ambiente de insatisfacción respondía a razones suficientes para que se presentaran los movimientos sociales que exigían un nuevo orden jurídico-político. Fue así como surgió la idea de un mecanismo electoral, diseñado por Fernando Carrillo ${ }^{45}$, denominado la "séptima papeleta" ${ }^{46}$, que

pública la nueva Carta: crecimiento del narcotráfico con los males que le eran anejos, como un aumento de la violencia y de la corrupción; la crisis política, derivada por una parte de un régimen político restrictivo propiciado desde el Frente Nacional, expresado en precarias o casi nulas posibilidades de participación política de otras fuerzas distintas a las del bipartidismo y por otra, derivada de una gran deslegitimación de la política tradicional en tanto no representaba los intereses del conglomerado social, y finalmente, una intensificación del conflicto armado colombiano entre guerrillas de un lado y del otro Estado y grupos paramilitares, que empezaban a obtener gran fuerza. El recrudecimiento de la violencia política durante la década del ochenta había propiciado la violación y limitación de los derechos humanos por parte de los grupos alzados en armas con su accionar y desde el propio Estado con la aplicación de las llamadas prácticas de la guerra sucia y las medidas legales tomadas a partir de la figura del estado de sitio, que como recurso supuestamente excepcional para restablecer el orden público turbado, fue la regla general en Colombia durante gran parte del siglo xx". Universidad de Antioquia. Antecedentes y contexto del surgimiento de la Constitución de 1991. Disponible en: http://docencia.udea.edu. co/derecho/constitucion/antecedentes.html (Consultado el 26 de febrero de 2017).

45 La idea de Carrillo, quien ejercía como docente de Hacienda Pública en la Universidad del Rosario, "consistía en invitar a los ciudadanos a depositar ese día una papeleta adicional cuyo texto 'voto por una asamblea nacional constituyente' serviría para expresar la voluntad de la nación, de manera directa, creando un hecho político inapelable en ejercicio de su poder constituyente". Torres, C. El estado de la opinión antes de la séptima papeleta. En Torres, M. et al., La Séptima Papeleta: historia contada por algunos de sus protagonistas con ocasión de los 20 años del Movimiento Estudiantil de la Séptima Papeleta. Bogotá: Universidad del Rosario, 2016, 72 .

46 "Recibió este nombre pues en esa fecha de elección se iba a votar por seis asuntos distintos, introduciendo 6 papeletas (senadores, representantes a la Cámara, diputados, alcaldes, concejales y consulta interna del Partido Liberal). Este mecanismo consistía en invitar al electorado a pronunciarse sobre la convocatoria de una Asamblea constitucional para reformar la carta política, mediante la utilización de una papeleta de votación, entonces mecanismo utilizado, que debía ser introducida en las urnas en las elecciones del 11 de marzo de 1990. A ese voto adicional lo bautizó con el nombre de la Séptima Papeleta, Sergio Ocampo, un periodista que, como muchos otros, creyó en nuestra propuesta al punto que divulgaba todos los pronunciamientos encabezados por la consigna 'Todavía Podemos Salvar a Colombia', que luego los medios convirtieron en el apelativo para identificar al grupo de los gestores de la Séptima Papeleta". ORTIZ, O. 20 años de la revolución ciudadana: una revolución en derecho y al derecho: de vasallos a ciudadanos. En Torres et al., La Séptima Papeleta: historia contada por algunos de sus protagonistas con ocasión de los 20 años del Movimiento Estudiantil de la Séptima Papeleta, cit., 98. 
se hacía eco de un movimiento estudiantil ${ }^{47}$ que contaba con la participación de cerca de 25.000 jóvenes $^{48}$ de distintas universidades ${ }^{49}$. La viabilidad de la "séptima papeleta" se despejaría el 27 de febrero de 1990, cuando el Registrador Nacional del Estado Civil conceptuó que la inclusión de ese voto en el sobre electoral no anularía los demás ${ }^{50}$. El 11 de marzo de 1990 un millón

47 "La muerte de Galán estremeció como ninguna otra los cimientos de una sociedad ya de por sí perpleja ante la escalada de violencia que vivía. Mientras el Gobierno como respuesta decretaba la extradición sin tratado por vía administrativa y la ocupación y decomiso de bienes vinculados al narcotráfico como castigo al enriquecimiento ilícito, entre otros, un grupo de estudiantes de la Facultad de Jurisprudencia de la Universidad del Rosario, apoyados por su rector, Roberto Arias Pérez; su decana, Marcela Monroy, y su vicedecano, Camilo Ospina, convocaban a estudiantes y profesores de otras universidades para que el jueves 24 de agosto participaran junto a ellos en una jornada de reflexión, cuyo propósito era organizar una marcha de protesta y definir qué acciones podrían tomar en medio de tamaño desafío institucional.

"La reunión tuvo lugar en la Universidad del Rosario y a ella asistieron principalmente estudiantes de las universidades Javeriana, Libre, Distrital, Nacional, los Andes, La Sabana, Externado, Jorge Tadeo, Gran Colombia, Sergio Arboleda y Central. Alrededor de los cinco temas de discusión acordados (poder ejecutivo, poder legislativo, rama judicial, orden público y economía) y del mensaje que debía ser transmitido al final de la marcha que se llevaría a cabo el día siguiente, se escucharon posiciones que ideológicamente recorrían toda la gama posible de colores del espectro político.

“Finalmente hubo acuerdo. La denominada 'Marcha del Silencio' fue multitudinaria y recibió un gran despliegue de los medios que no dudaron en catalogarla como 'histórica' por tener origen principalmente en la universidad privada, por su mensaje de rechazo a la violencia y apoyo a las instituciones democráticas, y por el compromiso de conformar un frente estudiantil que formule soluciones y sea capaz de plantearle al país las reformas que necesita". Torres. El estado de la opinión antes de la séptima papeleta, cit., 68.

48 "El plan de movilización se ponía en marcha. El Rosario debía esperar en la avenida Jiménez a los estudiantes de la Universidad de los Andes, Externado, La Gran Colombia y otras más. De ahí partiríamos recorriendo la $7 .{ }^{a}$ hasta la 26 , donde a su vez estarían ya los javerianos y la Universidad Distrital. Luego avanzando sobre la 26 se incorporaría la Universidad Nacional. Todo estaba conjurado. Los cálculos más optimistas estaban siendo grandemente superados. Los medios de comunicación daban cuenta de veinticinco mil estudiantes presentes y en total silencio. A diferencia de otras convocatorias sociales de esa especie, esa movilización no estuvo caracterizada por arengas o cánticos. Nada más diciente para ahogar el ruido de las balas que un incólume silencio. Así se dejó claro que esa era la última vez que nos quedaríamos callados. De ahí que esa marcha habría de ser conocida como la "Marcha del Silencio". Herrera, H. La Séptima Papeleta: la revolución de los estudiantes. En Torres et al., La Séptima Papeleta: historia contada por algunos de sus protagonistas con ocasión de los 20 años del Movimiento Estudiantil de la Séptima Papeleta, cit., 85.

49 "El propósito de la movilización estudiantil fue expresado en un comunicado leído el 25 de agosto de 1989, día de la marcha, mediante el cual se declaraba un rechazo directo a todo acto de violencia, sin importar su interés o ideología, se exigía el respeto por los derechos humanos en Colombia y se apoyaban las instituciones democráticas contra las fuerzas que quisieran desestabilizarlas, como paramilitares, guerrillas o narcotráfico. De igual forma, el documento solicitaba la convocatoria al pueblo para la reforma de algunas instituciones y se exigía la depuración de las fuerzas militares, de la policía, del gobierno y de los partidos políticos". LLERAS, C. y Tangarife, M. Constitución Política de Colombia: origen, evolución y vigencia. Medellín: Diké y Pontificia Universidad Javeriana, 1996, 13.

50 Sáchica, L. C. y Vidal Perdomo, J. La constituyente de 1991. Bogotá: Cámara de Comercio de Bogotá, 1991, 47. 
y medio de colombianos votaron por la "séptima papeleta" según escrutinios extraoficiales $^{51}$.

El proceso mismo se encargó de privar de protagonismo a los estudiantes, pues una vez el gobierno nacional decidió apoyar este movimiento social, la reforma pasó a ser más un punto de la agenda gubernamental que obra del pueblo. Es así como desde la expedición del Decreto 927 de 1990, el gobierno asumió la defensa de esta iniciativa popular.

Casi dos meses después de la votación, el Presidente Barco emite el Decreto Legislativo 927 del 3 de mayo de 1990, "Por el cual se dictan medidas tendientes al restablecimiento del orden público", reconociéndole de alguna manera el carácter constituyente al pronunciamiento electoral y abriendo la primera puerta de salida a la reforma. El articulado del Decreto resultó concreto y sencillo. Por un lado, ordenaba a la Registraduría desplegar todos los medios para contabilizar los votos que se produjesen en las elecciones presidenciales del 27 de mayo de 1990, frente a la disyuntiva de convocar o no a una Asamblea Constitucional, y por el otro determinaba el texto que contendría la tarjeta electoral con la que se le preguntaría al pueblo sobre dicha convocatoria ${ }^{52}$.

El decreto legislativo fue declarado exequible por la Corte Suprema de Justicia el 24 de mayo. Se dijo en uno de sus fundamentos:

... [el] juicio constitucional debe consultar la realidad social a la que se pretende aplicar una norma. Es necesario desbordar los cuadros de la pura estimativa jurídica para situarnos en el plano de la realidad social [...] El juez constitucional ha sido llamado juez estadista porque al ejercer el control normativo realiza juicios de valoración política. Nuestra Constitución precisamente se llama Constitución Política de Colombia, y quien ejerce funcionalmente su guarda es forzoso que emita juicios de contenido político, repito, en el buen sentido del vocablo ${ }^{53}$.

En las elecciones del 27 de mayo de 1990, la votación a favor de una asamblea nacional recibió un respaldo de "6”048.076 sufragantes: 5'236.863 votaron a favor de la Asamblea, y en contra 230.000" 54 .

El proceso electoral mencionado dejó como Presidente de la República electo al candidato liberal César Gaviria Trujillo, quien manifestó su apoyo al proceso de convocatoria a una asamblea nacional constituyente, no solo

51 Younes. Panorama de las reformas del Estado y de la administración pública, cit., 155.

52 ValenCia, H. Carta de batalla: una crítica al constitucionalismo colombiano. Bogotá: CERE, $1997,181$.

53 Corte Suprema de Justicia, Sala Plena. Sentencia de 25 de mayo de 1990, M.P.: Hernando Gómez Otálora y Fabio Morón Díaz.

54 Henao, J. Panorama del derecho constitucional colombiano. Bogotá: Temis, 2004, 108. 
por convicciones propias sino además porque en esa oportunidad triunfó la consulta a favor de convocar dicha asamblea. Así, Gaviria promovió un acuerdo político tendiente a convocarla y señalarle un temario, sobre la base de que su actuación se limitase a reformar la Constitución para fortalecer la democracia participativa. "Este acuerdo fue suscrito por Gaviria Trujillo, en su calidad de presidente electo y director nacional del partido liberal, y por representantes del Directorio Nacional Social Conservador, el Movimiento de Salvación Nacional y el Movimiento Alianza Democrática M-19, fuerzas que según el texto del acuerdo obtuvieron el 27 de mayo de 1996 más del 96\% de la votación total" ${ }^{55}$. Por ello, Gaviria, una vez posesionado, incorporó ese acuerdo político en el Decreto 1926 del 24 de agosto de 1990 (en ejercicio de las facultades de estado de sitio), convocando al electorado para el 9 de diciembre de 1990, para que decidiera sobre la aprobación o no de la convocatoria de una asamblea constitucional. Dijo el decreto en cita:

Artículo $1 .^{\circ}$ Mientras subsista turbado el orden público y en Estado de Sitio todo el territorio nacional, la Organización Electoral procederá a adoptar todas las medidas conducentes a contabilizar los votos que se emitan el 9 de diciembre de 1990, para que los ciudadanos tengan la posibilidad de convocar e integrar una Asamblea Constitucional.

Artículo 2. ${ }^{\circ}$ La papeleta que contabilizará la Organización Electoral deberá contener un voto afirmativo o un voto negativo.

El texto que deberá contener el voto afirmativo es el siguiente:

"Sí convoco una Asamblea Constitucional que sesionará entre el 5 de febrero y el 4 de julio de 1991, la cual estará regulada por lo establecido en el Acuerdo Político sobre la Asamblea Constitucional incorporado al Decreto 1926 de agosto 24 de 1990. Su competencia estará limitada a lo previsto en dicho acuerdo. Voto por la siguiente lista de candidatos para integrar la Asamblea Constitucional...".

Sin embargo, existía una batalla jurídica que aún faltaba por lidiar y que había sido perdida en ocasiones anteriores: la revisión constitucional al decreto de estado de sitio por la Corte Suprema de Justicia. Esta corporación tenía que pronunciarse sobre la constitucionalidad del Decreto Legislativo 1926 del 24 agosto 1990, y su decisión fue emitida el 9 de octubre de 1990 aceptando la ponencia de los magistrados Fabio Morón Díaz y Hernando Gómez Otálora. Sin embargo, a diferencia de ocasiones anteriores, la Corte dejó de lado las razones procesales de validez y declaró constitucional el decreto, aunque de manera parcial porque esta norma jurídica traía un listado taxativo de diez temas del llamado "Acuerdo político", lo que restringiría el "ejercicio pleno 
de la soberanía" al constituyente primario. Con esto, se abría la posibilidad para que la Asamblea reformara la totalidad del texto constitucional hasta el punto de crear una Constitución nueva y distinta. Desde este momento la Corte empezó a referirse a la asamblea como "asamblea constituyente" y ya no constitucional, pues daba vía libre para generar una nueva carta y no simplemente reformar puntos específicos de la de 1886. Sin embargo, el texto de la pregunta que sometida a aprobación del 9 de diciembre de 1990, y que aprobó el constituyente primario con una votación 3.600.000 a favor y 350.000 en contra fue el siguiente: "Con el fin de fortalecer la democracia participativa, ¿vota por la convocatoria a una asamblea nacional constitucional con representación de las fuerzas sociales, políticas y regionales de la nación, integrada democrática y popularmente, para reformar la Constitución de Colombia?".

El resultado de este proceso fue la escogencia de setenta miembros por el sistema de cociente electoral, de una lista de 119 candidatos incluidos en el tarjetón de elecciones.

Los setenta constituyentes o delegatarios elegidos representaron al Partido Liberal (24), al Movimiento Alianza Democrática M-19 (19), al Movimiento Salvación Nacional (11), al Partido Social Conservador (7), al conservatismo independiente (5), a la Unión Patriótica (2), al Movimiento Unidad Cristiana (2), y a las organizaciones indígenas (2). Posteriormente se sumaron 4 representantes de los grupos guerrilleros que abandonaron las armas conforme al proceso de paz dirigido por el gobierno ${ }^{56}$.

Los 74 constituyentes deliberaron durante cinco meses ( 5 de febrero de 1991 a 4 de julio de 1991) divididos en cinco comisiones, y estas en subcomisiones.

Obsérvese que la convocatoria fue para una asamblea constitucional, cuyo objetivo era reformar la Constitución vigente, pero la sociedad política y las instituciones estatales de inicios de los noventa consideraban que una asamblea constituyente permitiría reinventar un país mediante la integración de sus actores armados o no armados,

... y se presentaba como una oportunidad de generar las raíces de un pacto verdadero, donde el modelo económico, el diseño administrativo, la carta de derechos y los mecanismos de participación fueran el producto de un debate incluyente que estuviera basado en la igualdad y el respeto a la dignidad que todas las personas poseen, pero que requeriría un nuevo pacto político que reconociera esas bases como razón de ser del nuevo orden institucional ${ }^{57}$.

56 Ibíd., 110.

57 LeIva y MuÑoz. El poder constituyente y la Carta de Derechos en la Constitución Política de 1991, cit., 128. 
La Asamblea Nacional Constituyente expidió en mayo de 1991 el Acto Constituyente $n .^{\circ} 1$, mediante el cual se declaró con poder sin ningún límite y estableció que sus actos no estarían sujetos a ningún control de revisión judicial o de constitucionalidad. Por ello es posible afirmar que la Constitución de 1991 surge como manifestación del pueblo en ejercicio de su poder soberano como constituyente primario, tendiente a establecer un acuerdo político distinto al existente en aquel momento y que tuviese carácter normativo. Los propósitos de este contrato social se consagraron en la actual norma fundamental como un reflejo del proceso deliberativo que se afrontó antes y durante del funcionamiento de la Asamblea Nacional Constituyente ${ }^{58}$, finalidades que se encuentran expresadas a lo largo del texto constitucional. Así lo afirma la Corte Constitucional en uno de sus primeros pronunciamientos sobre el proceso constituyente de 1991:

La Asamblea Nacional Constituyente que expidió la nueva Constitución Política de Colombia fue un poder comisionado del pueblo soberano. La Constituyente actuó una vez superados los obstáculos que establecía el artículo 13 del plebiscito de 1957 para el pronunciamiento del constituyente primario, y en ese sentido las decisiones populares que permitieron la convocatoria hicieron irreversible el proceso de renovación institucional. La comprensión del proceso colombiano de reforma se encuentra pues en el concepto de anormalidad constitucional; y este concepto sólo puede ser definido políticamente, por ser acto fundacional, pues se refiere a un presupuesto del derecho que todavía no es jurídico. Este proceso de expresión del Poder Constituyente primario, en concepto de la Corte, es emanación especial del atributo incuestionable de las comunidades políticas democráticas que, en el Estado contemporáneo, pueden acudir de modo eventual y transitorio al ejercicio de sus potestades originarias para autoconformarse, $o$ para revisar y modificar las decisiones políticas fundamentales y para darle[s] a sus instituciones jurídicas, formas y contenidos nuevos con el fin de reordenar el marco de la regulación básica con una nueva orientación pluralista ${ }^{59}$.

\section{LA CARTA DE DERECHOS COMO EXPRESIÓN DEL NUEVO PACTO POLÍTICO}

La Asamblea Nacional Constituyente, como órgano representativo del constituyente primario, plasmó en la Constitución Política un querer que existía en la sociedad, consistente en un corpus mínimo de derechos fundamentales y garantías para su eficacia. De esta manera, la norma fundamental no sería exclusivamente acuerdo político sino norma jurídica vinculante para

58 "La Constitución es el orden jurídico fundamental expresado por un conjunto de normas que suelen tener base textual, mediante disposiciones reunidas en un documento formal, adoptado por el poder constituyente originario". Corte Constitucional. Sentencia C-588 de 2009 , M.P.: Gabriel Eduardo Mendoza Martelo.

59 Corte Constitucional. Sentencia C-544 de 1992, M.P.: Alejandro Martínez Caballero. 
todos los actores sociales, así como marco de legalidad funcional para las autoridades públicas. Esta construcción político-normativa fue producto de una amplia y controvertida actividad democrática. Sin embargo, este proceso deliberativo estableció que cualquier otra manifestación democrática y función estatal estaría limitada a respetar y garantizar el cumplimiento de uno de los presupuestos axiológicos fundamentales de las sociedades democráticas actuales y del constitucionalismo moderno: el principio de la dignidad humana ${ }^{60}$.

En efecto, la Constitución y las demás reglas normativas han establecido que el respeto a la dignidad humana es principio fundante del Estado de derecho ${ }^{61}$ moderno. Esta afirmación surge de la estrecha relación entre la dignidad humana -valor fundante del ordenamiento constitucional colombiano y principio orientador del derecho internacional de los derechos humanosy la eficacia de los derechos y garantías constitucionales como elemento esencial del Estado social de derecho ${ }^{62}$; este último como resultado de los procesos deliberativos que llevaron a la creación de la Asamblea Nacional Constituyente de 1991 y cuyas funciones estaban delimitadas a llevar el concepto de dignidad humana a fundamento funcional y ontológico del Estado colombiano (art. 1. ${ }^{\circ}$ de la Constitución Política) ${ }^{63}$.

$\mathrm{El}$ argumento anterior permite inferir que los procesos deliberativos y las funciones estatales están determinados por el reconocimiento de la dignidad humana como fundamento del orden constituido y una realización de la

60 "El derecho a la dignidad no es una facultad de la persona para adquirir su dignidad, ni para que el Estado se la otorgue o conceda, porque la dignidad es un atributo esencial de la persona humana; el derecho fundamental es a que se le dé un trato que respete plenamente la dignidad del ser humano. Es un derecho que implica tanto obligaciones de no hacer como obligaciones de hacer por parte del Estado". Corte Constitucional. Sentencia T-702 de 2001, M.P.: Marco Gerardo Monroy Cabra.

61 "La dignidad humana, como principio fundante del Estado, es el presupuesto esencial de la consagración y efectividad del sistema de derechos y garantías contemplado en la Constitución. Tiene valor absoluto no susceptible de ser limitado bajo ninguna circunstancia, lo que sí ocurre con derechos que necesariamente deben coexistir con otros y admiten variadas restricciones. El respeto a la dignidad humana no sólo es una declaración ética sino una norma jurídica de carácter vinculante para todas las autoridades. Su acato debe inspirar a todas las actuaciones del Estado. Por lo tanto, la dignidad del ser humano constituye razón de ser, principio y fin último de la organización estatal. Bajo este derrotero, la dignidad humana se erige como un derecho fundamental, de eficacia directa, cuyo reconocimiento general compromete el fundamento político del Estado colombiano". Corte Constitucional. Sentencia T-792 de 2005, M.P.: Clara Inés Vargas Hernández.

62 "El concepto de derecho fundamental, pese a inspirarse en la realidad y buscar en cierto modo moldearla, es fruto de la consagración o del reconocimiento del derecho positivo, de suerte que se impone encontrarse en un supuesto comprendido dentro de su ámbito material delimitado o supuesto por el Constituyente para poder gozar de él". Corte Constitucional. Sentencia T-240 de 1993, M.P.: Eduardo Cifuentes Muñoz.

63 Corte Constitucional. Sentencia T-585 de 2008, M.P.: Humberto Antonio Sierra Porto. 
democracia pluralista como alternativa de organización política y jurídica ${ }^{64}$. El reconocimiento de la dignidad humana como piedra angular de los modernos sistemas sociales conduce a la afirmación del carácter personalista del Estado, una concepción en la que la persona humana es el fin que se ha de realizar, valiéndose para ello del Estado y del derecho como instrumentos y no como fines en sí mismos, y mucho menos como entidades dotadas de unos atributos que solo le asisten a ella. La democracia pluralista no es más que una consecuencia desprendida de la dignidad humana ${ }^{65}$ que permite la consagración y garantía de los derechos humanos ${ }^{66}$, así como su adecuada interpretación ${ }^{67}$.

Por lo anterior, la relación entre proceso deliberativo, constitución como norma jurídico-política y derechos humanos es directa. En efecto, el primero

64 "Como puede advertirse, el Texto Superior constituye un sistema normativo. No se trata de una simple aglomeración de prescripciones emanadas del constituyente. En él se advierte una teleología definida; una afirmación de valores, principios y derechos que parten del reconocimiento del hombre como un ser digno y de la asunción de la democracia pluralista como un mecanismo de realización de esa dignidad. De igual manera, se advierte en la Carta una concepción instrumental y no finalística del Estado y una detallada regulación que no sólo se orienta a racionalizar el ejercicio del poder público mediante su división, sino también a dotarlo de una estructura que resulte adecuada para la realización de sus fines. Así, cada una de las disposiciones del Estatuto Superior tiene un sentido propio que se determina a partir de su propio texto, pero también desde la perspectiva del sistema que contribuye a integrar y definir". Corte Constitucional. Sentencia C-879 de 2003, M.P.: Jaime Córdoba Triviño.

65 "Sólo los regímenes democráticos y pluralistas suministran el contexto político y jurídico requerido para que la persona humana no se instrumentalice y para que realice o procure la realización de todas sus potencialidades como un ser racional, libre y responsable. Una democracia constitucional sólo se realiza si cada instancia pública de decisión tiene como norte permanente y no coyuntural la afirmación del cúmulo de atributos que a la manera de derechos fundamentales afirman la dignidad del hombre y sólo si la conformación, ejercicio y control del poder político se asumen con un amplio reconocimiento de espacios de participación ciudadana". Corte Constitucional. Sentencia T-299 de 2003, M.P.: Jaime Córdoba Triviño.

66 "Lo más importante de la nueva Constitución fue determinar una Carta de Derechos. En efecto, sus primeros 102 artículos contienen los principios fundamentales, derechos, garantías, derechos colectivos y las formas de su protección y aplicación. Este listado de derechos no es cerrado porque existe expresa remisión a los instrumentos internacionales cuando consagran derechos humanos, luego es más completo que el que contenía la Constitución anterior y tiene una visión amplia y específica de la sociedad; un ejemplo: la consagración expresa de los derechos de los niños, los jóvenes, las mujeres, los ancianos y las personas con alguna discapacidad". Delgado, O. et al. Constituciones y control constitucional en Colombia. En Cortés, J. et al., Itinerario de la jurisprudencia colombiana de control constitucional como mecanismo de protección de derechos humanos. Bogotá: Universidad del Rosario, 2009, 99-100.

67 La clasificación entre parte orgánica y parte dogmática es la que permite una integralidad conceptual vinculante cuando de interpretación la Constitución se trata: "La Corte tendrá en cuenta la distinción clásica que la doctrina constitucional suele establecer entre la parte dogmática y la parte orgánica de los textos constitucionales. La primera contiene los principios filosóficos que orientan la organización estatal y definen las relaciones básicas entre los ciudadanos y las autoridades, mientras que la segunda regula la organización institucional y territorial del Estado". Corte Constitucional. Sentencia C-251 de 2002, M.P.: Eduardo Montealegre Lynett y Clara Inés Vargas Hernández. 
permite una interacción de argumentos que contribuyen a darle el carácter que la sociedad requiere para su marco institucional, y este gozar de un marco axiológico, positivo y vinculante para todas las autoridades públicas y las demás personas que participan en la realización de los fines esenciales del Estado ${ }^{68}$. Por ello, el pacto que surge de la reciprocidad de voluntades expresada por los actores sociales se vuelve una obligación para todos los participantes en ese proceso deliberativo-pacta sunt servanda-y que requiere de su materialización a través de un documento que contribuya a formalizar las cláusulas contractuales para que produzca efectos jurídicos - ad substantiam actus - y exigir su cumplimiento en caso de vulneración por parte de los contratantes. Estas cláusulas son las disposiciones constitucionales y se deberán interpretar según los principios acordados en el proceso deliberativo, especialmente el del respeto de la dignidad. Por ende, la relación entre el proceso deliberativo (etapas previas al contrato social), la constitución política (texto normativo ad substantiam actus) y los derechos fundamentales y demás disposiciones constitucionales es directa, y el desconocimiento de los acuerdos pactados implica una renuncia del Estado a sus más elementales funciones constitucionales, a la vez que constituye un incumplimiento de su misión y razón de ser" ${ }^{69}$, pues ello significa dejar "los derechos constitucionales indefensos y un quiebre del orden jurídico-político pactado y materializado en la Constitución Política"70.

\section{CONCLUSIONES}

La Asamblea Nacional Constituyente que expidió la Constitución Política de 1991 fue un poder comisionado que surgió como consecuencia de las deliberaciones de los actores políticos que vieron en la creación de un nuevo pacto político la manera de hacerle frente a la compleja situación de violencia que

68 "De acuerdo con lo que establece el artículo 95 de la Constitución, el ejercicio de los derechos y libertades reconocidos en ella implica responsabilidades. Estas y aquéllos tienen vocación de realización objetiva y entre los fines esenciales e impostergables del Estado figura el de garantizar su efectividad (art. 2 C.P.), lo que compromete a las ramas y órganos del poder público a propender que $[$ sic] tales derechos y deberes salgan del plano teórico y tengan cabal realización.

"Una correcta aplicación de las normas constitucionales debe reflejarse en el equilibrio entre derechos y deberes, merced a la ponderación de los factores que inciden en la circunstancia específica, dentro de los principios generales de justicia, seguridad jurídica y equidad". Corte Constitucional. Sentencia C-657 de 1997, M.P.: José Gregorio Hernández Galindo.

69 "El Estado sólo existe por los derechos y ha sido creado para garantizarlos; la fundamentación, justificación y legitimación del orden coactivo jurídico monopolizado por el Estado solo se da en función de los derechos, como categoría jurídica consignada en el primer nivel normativo de un país. De allí que lo primero que debe hacer la constitución es enumerar esos derechos fundamentales y sus mecanismos de protección". Delgado, O. et al. Ideas políticas, filosofía y derecho: el maestro. Bogotá, Universidad del Rosario, 2006, 309.

70 Corte Constitucional. Sentencia T-958 de 2002, M.P.: Eduardo Montealegre Lynett. 
enfrontaba la sociedad colombiana a finales del siglo xx. Su legitimidad era fáctica, pues provino de un hecho político-fundacional que contrarió el régimen jurídico vigente en ese momento. En este sentido, el proceso colombiano de reforma se enmarca dentro del concepto de anormalidad constitucional, que solo puede ser definido políticamente, como un acto fundacional - un nuevo pacto político- pues se refiere a un presupuesto del derecho que todavía no es jurídico. Sin embargo, su validez como norma jurídica y su legitimidad como acuerdo político no pueden ser cuestionados por el hecho mismo de haber desatendido el procedimiento normativo de reforma constitucional anterior a su creación. La validez de una norma del ordenamiento jurídico puede ser analizada exclusivamente a partir de sus formalidades previas. Pero la validez del ordenamiento es un concepto que depende de un hecho que le precede y convive con él: la eficacia. La norma fundamental ideada por Kelsen ${ }^{71}$ no es otra cosa que la eficacia del ordenamiento o la regla de reconocimiento concebida por $\mathrm{Hart}^{72}$. Por eso, cuando una constitución es reemplazada por otra que termina siendo eficaz no tiene sentido cuestionar su validez. "En este caso, el análisis de continuidad de las condiciones de lo moral, lo axiológico y lo jurídico resulta inocua pues es obvio que no existirá una continuidad lógico-jurídica entre el derogado ordenamiento constitucional y aquel que lo sustituye" 73 . Por lo anterior, la legitimidad del proceso deliberativo constituyente que condujo a la expedición de la Constitución de 1991 no reside en el acto jurídico sino en el hecho político que reconocería la sublevación ante un ordenamiento jurídico que no reflejaba los intereses de los actores sociales que interactúan para la construcción de un nuevo pacto social ${ }^{74}$. Por esta razón, la Constitución de 1991 puede ser considerada

71 Kelsen, H. Teoría pura del derecho. Buenos Aires: Eudeba, 1994, 130. A juicio de Kelsen, con el término "fuente del derecho" se pueden entender todos los medios de producción jurídica, y también el fundamento de la validez, en particular, el fundamento último de la validez de un ordenamiento jurídico, esto es, la norma fundamental. Pero, de hecho -señala Kelsen-, se define como "fuente" solo el fundamento de derecho positivo de la validez de una norma jurídica, o sea, la norma jurídica superior que regula la producción. En este sentido, la constitución es la fuente de las normas jurídicas generales producidas mediante la legislación y la costumbre. Pérez, A. Trayectorias contemporáneas de la filosofía del derecho. Madrid: Tebar, 2007, 40.

72 Hart, H. L. A. El concepto de derecho. Bueno Aires: Abeledo-Perrot, 2007, 125 a 137.

73 LeIva y MuÑoz. El poder constituyente y la Carta de Derechos en la Constitución Política de 1991, cit., 130.

74 "El proceso que condujo a la promulgación de la Constitución Política de 1991 fue producto de un anhelo nacional que deseaba una mayor participación política en las decisiones que les afectaban, especialmente en la búsqueda de un escenario que permitiera la estabilización hacia la paz nacional que aparentemente se estaba alcanzado con la desmovilización de grupos guerrilleros como el M-19, pero que se estaba viendo afectada con la entrada de la violencia que producían los grupos de narcotraficantes, la cual tuvo su mayor representación con la muerte de Rodrigo Lara Bonilla, Luis Carlos Galán, Carlos Pizarro, Jaime Pardo Leal, Bernardo Jaramillo Ossa, entre otros dirigentes; lo que conllevó a [sic] que la sociedad reaccionara, siendo el movimiento estudiantil su mayor exponente a través del movimiento conocido como la 'séptima 
como una manifestación del poder constituyente primario que decidió darse un nuevo ordenamiento jurídico para obtener, entre otras cosas, una mayor participación en las decisiones políticas del Estado, una eficacia y garantía de los derechos fundamentales de los asociado, bien sea como producto de una aplicación inmediata de los mismos o como consecuencia del ejercicio de los mecanismos y acciones consagrados para este propósito, una nueva organización del Estado, y procesos precisos de reforma constitucional. Sin embargo, la teoría del poder constituyente es necesaria mas no suficiente para explicar de manera razonable, democrática y humanista los cambios políticos-jurídicos.

En efecto, las democracias constitucionales actuales no pueden ser entendidas únicamente bajo los argumentos del hecho político, de la fuerza, de la revolución y de la ruptura institucional, para la comprensión íntegra del poder constituyente. Es necesario que los cambios sean democráticos y garanticen la libertad, la justicia, la igualdad y los demás valores indispensables para legitimarlos. Estos son los límites axiológicos que deben respetar los actores políticos que participan en el proceso deliberativo, pues el desconocimiento de estos requisitos de validez axiológica haría del pacto un acuerdo ilícito no por su ilegalidad sino por desconocer los principios democráticos y humanísticos que le darían legitimidad al resultado de esa deliberación ${ }^{75}$. "Aceptar un proceso deliberativo constituyente que desconozca los límites de legitimidad podría justificar regímenes contrarios a la dignidad del hombre" 76 .

Uno de los objetivos de las constituciones y la razón de mantener su condición de norma suprema en la escala del ordenamiento jurídico es el de estructurar para la comunidad el Estado de derecho ${ }^{77}$, entendido como

papeleta', el cual motivó a los Gobiernos de Virgilio Barco y César Gaviria a diseñar los instrumentos jurídicos que permitieran una modificación a la Constitución Nacional de 1886.

"La sentencia de la entonces Sala Constitucional de la Corte Suprema de Justicia, donde estudia el decreto 1296 de 1990, dio paso para que no se reformara la Constitución Nacional de 1886, sino que esta fuera derogada y se diera paso a una nueva Carta Política, teniendo como génesis el año de 1991”. Ibíd., 131.

75 “Puede una democracia establecer o tolerar las condiciones para su propia muerte? Sí y no. Sí, porque el poder constituyente puede reaparecer con toda su potencialidad en los periodos de anormalidad constitucional y retomar su facultad -ilimitada y permanente- para reformar todo el ordenamiento. Y no, porque las nuevas instituciones que se den en un pueblo deben ser humanistas, democráticas y razonables". Corte Constitucional. Sentencia C-544 de 1992, M.P.: Alejandro Martínez Caballero.

76 Leiva y MuÑoz. El poder constituyente y la Carta de Derechos en la Constitución Política de 1991, cit., 131. Para Konrad Hesse, el "problema central de la teoría y de la política constitucional del presente y del inmediato futuro" es el de "cómo debe comprenderse y desarrollarse la Constitución bajo las condiciones del mundo técnico moderno a fin de poder cumplir su función en la vida de la Comunidad, la de cooperar a posibilitar y preservar la libertad y, en inmediata conexión con ella, la democracia”. Hesse, K. Escritos de derecho constitucional. Madrid: Centro de Estudios Constitucionales, 1992, XI.

77 Así lo ha entendido la Corte Constitucional al establecer la importancia del artículo 2. ${ }^{\circ}$ constitucional: "Una de las finalidades básicas de las autoridades colombianas es la defensa 
aquel que procura garantizar a los coasociados el equilibrio y la armonía en las relaciones políticas, económicas y jurídicas, asegurando un orden justo y autónomo ${ }^{78}$. Por eso, la mayoría de los textos constitucionales se diseñan bajo el supuesto de orden y normalidad, estableciendo los parámetros generales de la actividad y el comportamiento de los organismos estatales, de los gobernantes y gobernados en situaciones de paz, con el fin de asegurar que dichas situaciones constituyan el eje central del funcionamiento del Estado y tengan efecto de permanencia (Corte Constitucional, sentencia C-008 de 2003). Esto es observable a través del contenido normativo y axiológico de la Constitución Política de $1991^{[79]}$, especialmente en lo que concierne al

de la integridad nacional y la preservación del orden público y de la convivencia pacífica, no sólo porque así lo establece expresamente el artículo $2{ }^{\circ}$ de la Carta, sino además porque esos elementos son condiciones materiales para que las personas puedan gozar de sus derechos y libertades. La Constitución busca entonces el fortalecimiento de las instituciones, para que éstas puedan cumplir efectivamente su misión constitucional de asegurar la convivencia pacífica perturbada por grupos armados que actúan al margen de la ley y atentan contra la vida, la libertad y los demás derechos y libertades de las personas residentes en Colombia (CP art. 2. ${ }^{\circ}$ ). Por ello esta Corte señaló que el Estado tiene el deber de 'mantener la convivencia pacífica e instaurar un sistema jurídico-político estable, para constituir la protección a la vida como una de las obligaciones del gobernante sin las cuales no es posible la continuidad de la comunidad', puesto que el derecho 'sólo puede asegurar al individuo una esfera de libertad y protección contra la violencia a condición de reprimir, incluso con la fuerza, aquellas actividades violentas de los demás individuos que vulneran esa órbita de libertad"'. Corte Constitucional. Sentencia C-251 de 2002, M.P.: Eduardo Montealegre Lynett y Clara Inés Vargas Hernández.

78 Sobre este tema, se traen a colación las palabras dichas por Rodolfo Arango: "Yendo más allá, a la interpretación de la Constitución, yo diría que la Constitución es como las obras de arte, que una vez creadas adquieren una vida independiente, una vida propia. Casi podríamos decir que se separan de su autor, y no hay entonces que estar consultando exclusivamente qué se quiso hacer, qué se quiso decir. Porque los tiempos están cambiando, cambian minuto a minuto las circunstancias, y la función del intérprete es precisamente acomodar la norma jurídica a los nuevos tiempos, a las nuevas circunstancias sociales, económicas y políticas. Sin perder de vista la finalidad del derecho que es realizar dos valores fundamentales: la seguridad jurídica y la justicia”.

79 "La Constitución colombiana recoge ampliamente los postulados normativos del Estado Social de Derecho. Ello se comprueba no solo al repasar lo consagrado en la lista de los principios y de la Carta de derechos, sino también en la organización de otros elementos propios de un acuerdo político. Así, la constitución actual consagra El Preámbulo anuncia ya los fines por los cuales el pueblo colombiano se constituyó en un Estado social y democrático de derecho. Luego, establece los principios fundamentales que rigen su estructura política y jurídica y reconoce los derechos y garantías que amparan a todas las personas residentes en Colombia, los deberes que las vinculan y configura los mecanismos de protección de tales derechos y garantías. Después, regula lo relacionado con los habitantes y el territorio, como elementos del Estado constituido, y con los mecanismos a través de los cuales se ejerce la soberanía popular. Subsiguientemente, se ocupa de la estructura del Estado instituyendo las ramas del poder público, los órganos de control y la organización electoral que integran esa estructura, y los fundamentos constitucionales que rigen el ejercicio de la función pública. Luego regula la organización electoral y los órganos de control: Contraloría General de la República y Ministerio Público. Posteriormente, prescribe los fundamentos de la organización territorial y del régimen económico y de la hacienda pública. Finalmente, regula los mecanismos de reforma de la Constitución y el procedimiento a que se 
equilibrio entre derechos y deberes que los actores políticos que participaron en el proceso deliberativo acordaron en el momento de suscribir el pacto constitucional $^{80}$. Por esta razón, la Constitución de 1991 es un pacto jurídicopolítico que surge de procesos constituyentes deliberativos que plasman un conjunto de derechos con contenido político y axiológico que obliga a interpretar su contenido más allá de su articulado, sin que ello signifique que la formalidad escrita de la Constitución deba ser desconocida, pues estas son las cláusulas contractuales del pacto político ${ }^{81}$.

En este sentido, la tipificación de los derechos humanos (o fundamentales, como los denomina la Constitución de 1991) es el producto del ejercicio legítimo que tienen los actores sociales de iniciar un proceso deliberativo a través del cual acuerdan plasmar estas cláusulas contractuales a través de los mandatarios que les representaron en la Asamblea Nacional Constituyente. Corporación que, en cuanto cuerpo político, usó su poder soberano para consagrar unos parámetros mínimos en el nuevo pacto social, como la paz, la justicia, el trabajo, la convivencia y la igualdad entre los miembros del Estado, y los principios y valores democráticos. De esta forma, los delegados constituyentes cumplieron el mandato conferido por los actores sociales que participaron en el proceso deliberativo. Por ello, a pesar de las circunstancias que aquejen a la sociedad colombiana, la Constitución Política sigue siendo

sujeta cada uno de ellos". LeIva, E. La responsabilidad del Estado por el hecho del legislador. Bogotá: Ibáñez, 2010, 28.

80 "La doctrina de esta Corte ha observado en incontables ocasiones que la Constitución Política no sólo reconoce derechos en cabeza de las personas sino que contempla obligaciones, deberes y cargas, correlativos a aquéllos, cuyo cumplimiento se exige a los asociados como factor insustituible para la efectiva vigencia de los postulados y mandatos constitucionales y para la realización de un orden jurídico, económico y social justo, como lo preconiza la Carta desde su mismo Preámbulo". Corte Constitucional. Sentencia C-657 de 1997, M.P.: José Gregorio Hernández Galindo.

81 "La formalización de las constituciones que de tal manera tiene lugar se vale, entonces, de dos elementos importantes: la escritura y la unidad documental o unicidad del texto, pues la Constitución, fuera de expresar por escrito los enunciados que conforman el orden jurídico fundamental del Estado constitucional, los reúne, concentra o codifica en un solo documento, sin que al efecto importe que los enunciados recogidos en el texto sean de diverso signo y respondan a diferentes criterios de clasificación, pues la Constitución más que una norma es un conjunto de normas o un cuerpo normativo. Las finalidades de la utilización de la escritura y de la codificación son las de fijar los contenidos básicos que fundan el ordenamiento jurídico y facilitar su conocimiento y consulta, sobre todo si, por su carácter normativo, la Constitución se incorpora al sistema de fuentes del Derecho, está al alcance de todos y vincula a los poderes públicos y a los particulares. Asimismo, la formalización en un solo documento escrito también tiene el muy importante cometido de proporcionar certeza respecto del contenido de la Constitución y de afianzar la seguridad jurídica desde el más alto nivel del ordenamiento. La tendencia de permanecer con un contenido inalterado y en forma completa no se opone a la necesidad del cambio requerido por la variación histórica de las circunstancias ni a la consecuente actualización de los contenidos superiores del ordenamiento, que bien puede hallar su cauce en una interpretación dinámica o evolutiva de la Constitución escrita". Corte Constitucional. Sentencia C-588 de 2009, M.P.: Gabriel Eduardo Mendoza Martelo. 
un pacto jurídico-político que garantiza y protege los derechos humanos de los habitantes del territorio nacional. Seguramente, de no existir, la situación social sería mucho más grave. Por ejemplo, gracias a mecanismos como la acción de tutela, la Carta Política colombiana es normativa y no meramente nominal, lo que le ha permitido un elevado dinamismo en la aplicación y garantía de los derechos fundamentales. Así lo quisieron los actores sociales que participaron en el proceso deliberativo constituyente, y los delegados lo plasmaron en la Constitución en cumplimiento del legítimo mandato entregado por el constituyente primario.

\section{REFERENCIAS}

Alviar, H. y Villegas, C. La función social de la propiedad en las constituciones colombianas. Bogotá: Universidad de los Andes, 2012.

Amador, S. El camino de la Constitución de 1991: diario de la exclusión. En: Quintana, O. et al., Poder constituyente, conflicto y Constitución en Colombia. Bogotá: Universidad de los Andes, Bogotá. 2005.

Barreto, A. La generación del estado de sitio. Bogotá: Universidad de Los Andes, 2011.

Colomer, A. Comunidades y ciudades, constituciones y solidaridades. Valencia: Universidad Politécnica de Valencia, 2007.

Delgado, O. et al. Ideas políticas, filosofía y derecho: el maestro. Bogotá: Universidad del Rosario, 2006.

Delgado, O. et al. Constituciones y control constitucional en Colombia. En: Cortés, J. et al., Itinerario de la jurisprudencia colombiana de control constitucional como mecanismo de protección de derechos humanos. Bogotá: Universidad del Rosario, 2009.

De Sousa Santos, B. y García Villegas, M. El caleidoscopio de las justicias en Colombia. Bogotá: Siglo xxi Editores, 2001.

ELSTER J. Ulises desatado: estudios sobre racionalidad, precompromiso y restricciones. Barcelona: Gedisa, 2002.

Ferrajoli, L. Derecho y razón: teoría del garantismo penal. Madrid: Trotta, 1995.

Ferrajoli, L. Principia iuris: teoría del derecho y de la democracia. Madrid: Trotta, 2011.

Habermas, J. Teoría de la acción comunicativa: racionalidad de la acción y racionalización social. Madrid: Taurus, 1987.

Hart, H. L. A. El concepto de derecho. Buenos Aires: Abeledo-Perrot, 2007.

Henao, J. Panorama del derecho constitucional colombiano. Bogotá: Temis, 2004.

Herrera, H. La Séptima Papeleta: la revolución de los estudiantes. En Torres, M. et al., La Séptima Papeleta: historia contada por algunos de sus protagonistas con 
ocasión de los 20 años del Movimiento Estudiantil de la Séptima Papeleta. Bogotá: Universidad del Rosario, 2016.

Hesse, K. Escritos de derecho constitucional. Madrid: Centro de Estudios Constitucionales, 1992.

Kelsen, H. Teoría pura del derecho. Buenos Aires: Eudeba, 1994.

LeIVA, E. La responsabilidad del Estado por el hecho del legislador. Bogotá: Ibáñez, 2010.

Leiva, E. y Muñoz, A. El poder constituyente y la Carta de Derechos en la Constitución Política de 1991. En Revista Administración \& Desarrollo. Vol. 39, n. ${ }^{\circ}$ 54, 2011.

LeIva, E. La influencia de las Tic y la educación cívica en los procesos deliberativos de las sociedades pluralistas. En Revista de Derecho, Comunicaciones y Nuevas Tecnologías. N. ${ }^{\circ}$ 14. 2015.

Lleras, C. y Tangarife, M. Constitución Política de Colombia: origen, evolución y vigencia. Medellín: Diké y Pontificia Universidad Javeriana, 1996.

Martí, J. La república deliberativa: una teoría de la democracia. Madrid: Gedisa, 2006.

Moncayo, V. El Leviatán derrotado: reflexiones sobre teoría del Estado y el caso colombiano. Bogotá: Norma, 2004.

ORTIZ, O. 20 años de la revolución ciudadana: una revolución en derecho y al derecho: de vasallos a ciudadanos. En Torres, M. et al., La Séptima Papeleta: historia contada por algunos de sus protagonistas con ocasión de los 20 años del Movimiento Estudiantil de la Séptima Papeleta. Bogotá: Universidad del Rosario, 2016.

PÉREZ, A. Trayectorias contemporáneas de la filosofía del derecho. Madrid: Tebar, 2007.

PRIETO, L. Derechos fundamentales, neoconstitucionalismo y ponderación judicial. Lima: Palestra, 2002.

RodríGuez, C. La globalización del Estado de derecho. Bogotá: Universidad de los Andes, 2009.

SÁchICA, L. C. y Vidal Perdomo, J. La constituyente de 1991. Bogotá: Cámara de Comercio de Bogotá, 1991.

Torres, C. El estado de la opinión antes de la Séptima Papeleta. En Torres, M. et al., La Séptima Papeleta: historia contada por algunos de sus protagonistas con ocasión de los 20 años del Movimiento Estudiantil de la Séptima Papeleta. Bogotá: Universidad del Rosario, 2016.

Universidad de Antioquia. Antecedentes y contexto del surgimiento de la Constitución de 1991. Disponible en: http://docencia.udea.edu.co/derecho/constitucion/antecedentes. html (Consultado el 26 de febrero de 2017).

Valencia, H. Carta de batalla: una crítica al constitucionalismo colombiano. Bogotá: CERE, 1997. 
VERDESOTO, L. Procesos constituyentes y reforma institucional: nociones para comprender y actuar en el caso ecuatoriano. Quito: Abya-Yala, 2007.

WALUCHOW, W. Una teoría del control judicial de constitucionalidad basada en el commom law: un árbol vivo. Madrid: Marcial Pons, 2009.

Younes Moreno, D. Panorama de las reformas del Estado y de la Administración Pública. Bogotá: Universidad del Rosario, 2004.

\section{Jurisprudencia de la Corte Constitucional}

Auto A003 del 3 de marzo de 1992, M.P.: Alejandro Martínez Caballero.

Sentencia T-406 del 5 de junio de 1992, M.P.: Ciro Angarita Barón.

Sentencia C-544 del 1. ${ }^{\circ}$ de octubre de 1992, M.P.: Alejandro Martínez Caballero.

Sentencia T-240 del 23 de junio 23 1993, M.P.: Eduardo Cifuentes Muñoz.

Sentencia C-657 del 3 de diciembre de 1997, M.P.: José Gregorio Hernández Galindo.

Sentencia T-702 del 5 de julio de 2001, M.P.: Marco Gerardo Monroy Cabra.

Sentencia C-251 del 11 de abril de 2002, M.P.: Eduardo Montealegre Lynett y Clara Inés Vargas Hernández.

Sentencia T-958 del 7 de noviembre de 2002, M.P.: Eduardo Montealegre Lynett.

Sentencia C-008 del 23 de enero de 2003, M.P.: Rodrigo Escobar Gil.

Sentencia T-299 del 11 de abril de 2003, M.P.: Jaime Córdoba Triviño.

Sentencia C-551 del 9 de julio de 2003, M.P.: Eduardo Montealegre Lynett.

Sentencia C-879 del 30 de septiembre de 2003, M.P.: Jaime Córdoba Triviño.

Sentencia T-792 del 28 de julio de 2005, M.P.: Clara Inés Vargas Hernández.

Sentencia C-180 del 14 de marzo de 2007, M.P.: Rodrigo Escobar Gil.

Sentencia T-585 del 12 de junio de 2008, M.P.: Humberto Antonio Sierra Porto.

Sentencia C-588 del 27 de agosto de 2009, M.P.: Gabriel Eduardo Mendoza Martelo.

Sentencia C-141 del 26 de febrero de 2010, M.P.: Humberto Antonio Sierra Porto. 